\title{
Maurice Ravel \\ e a Guerra
}

\author{
Danieli V. L. Benedetti \\ (Cruzeiro do Sul/USP/FAPESP)
}

\begin{abstract}
Resumo: o presente texto, segmento de pesquisa de doutorado realizada no Departamento de Música da ECA/USP, com o apoio da FAPESP, pretende fazer uma reflexão sobre a correspondência do compositor francês Maurice Ravel (1875-1937), voltando-se mais especificamente ao período da Primeira Guerra Mundial (19141918). Fundamentado em trabalhos referenciais e no importante acervo da correspondência do compositor, de posse da Bibliothèque Nationale de France - BNF, o presente texto pretende questionar a que ponto a ideia fixa pela defesa da pátria tomou conta da vida do compositor, influenciando sua produção musical do período em questão.
\end{abstract}

Palavras-chave: Maurice Ravel, correspondência, amigos, conflitos, guerra.

\section{MAURICE RAVEL AND THE WAR}

Abstract: This study, part of a doctoral research carried out in the Department of Music at the ECA / USP, with the support of FAPESP, intends to reflect about the correspondence of the French composer Maurice Ravel (1875-1937), specifically during the First World War (1914-1918). Based on works of reference and on the important collection of the composer's letters of the Bibliothèque Nationale de France - BNF, this paper aims to question how far the obsession of defending the homeland took over in the composer's life, influencing his musical production of this period.

Keywords: Maurice Ravel, correspondence, friends, conflicts, war. 
A correspondência de Ravel é extensa. De acordo com Arbie Orenstein, o compositor teria escrito durante sua vida por volta de 1500 cartas, parcialmente publicadas. Existem três trabalhos dedicados a correspondência de Ravel: Ravel au miroir de ses lettres, livro raro e antigo organizado por René Chalupt em 1956, no qual encontramos 190 cartas; Lettres à Roland Manuel et à sa famille, no qual Jean Roy reúne a correspondência do compositor com o amigo e primeiro biógrafo Roland Manuel e sua mãe, a senhora Fernand Dreyfus, figura importante na vida do compositor (publicado em 1986); e Maurice Ravel - Lettres, écris, entretiens, organizado por Arbie Orenstein, musicólogo e especialista da vida e obra do compositor, em que reúne, após 20 anos de pesquisa, o essencial da correspondência de Maurice Ravel, 350 cartas inéditas até então (este publicado em 1989). O resultado desse último é uma espécie de jornal íntimo de sua carreira, no qual podemos descobrir seus gostos pessoais, seu amadurecimento artístico, alegrias, tristezas, frustrações, seus pontos de vista sobre a vida musical francesa e o período que serviu como soldado durante os anos da Primeira Guerra Mundial (1914-1918), fase dedicada ao presente artigo. Segundo Orenstein, todas as suas cartas são escritas em francês, único idioma que o compositor falava fluentemente, e quase sempre eram datadas. A maioria das cartas se destina a amigos íntimos, e por esse motivo faz uso de uma linguagem bastante informal, com um vocabulário que comporta algumas expressões populares e gírias.

Em pesquisa de campo realizada em Paris, foi possível analisar o acervo das lettres autographes da Bibliothèque National de France, que possui um grande número de cartas de Maurice Ravel, trocadas entre 1900 e 1933, a maioria escritas durante a Primeira Guerra, e das quais muitas se encontram transcritas no trabalho de Orenstein. Esses documentos encontram-se em perfeito estado de conservação, quase todos acompanhados do respectivo envelope e fica evidente, assim como em seus manuscritos musicais, o cuidado por parte de Ravel no que diz respeito a clareza dos textos e de sua caligrafia, nos quais raramente

\footnotetext{
${ }^{1}$ Cartas autografas.
} 
encontra-se uma rasura ou rascunho. Esse detalhe só foi notado na correspondência trocada no final da vida do compositor que, devido a doença que Ihe acometeu ${ }^{2}$ teve afetado os movimentos das mãos. Todo o acervo referente as lettres autographes da BNF foi catalogado por A. Bloch-Michel, sendo as cartas de Maurice Ravel organizadas no volume 89 e 90, assim codificadas: BnF. Mu. L.a. Ravel, seguido do número colocado no canto direito abaixo do documento. Todas as traduções aqui apresentadas são de minha autoria e foram realizadas fidedignas ao texto original.

Em primeiro de agosto de 1914 a Alemanha declara guerra à França, e Maurice Ravel, cidadão da Terceira República revanchista ${ }^{3}$, assim como todos os franceses, sentir-se-ia aliado à defesa nacional.

O escritor Roger Martin du Gard (1881-1958), contemporâneo do compositor Maurice Ravel, Prêmio Nobel da Literatura em 1937, descreveu com clareza em sua obra Les Thibault, o clima que se instala na França no exato momento da declaração da Guerra. Traduzo e transcrevo o trecho tirado do volume O Verão de 1914, em que o autor escreve sobre a necessidade para um francês de defender o seu país:

Uma coisa é certa e prioritária: pertencemos a um país que não queria a guerra e que nada tem a se censurar. Já os alemães não podem dizer isso! A paz depende deles! Tiveram por dez vezes, em quinze dias, a ocasião de barrar o caminho para a guerra - nós também poderíamos ter dito merda à Rússia - Nada nos impediria! Hoje percebemos que os alemães haviam tramado de forma suja esse golpe! Então azar o deles! Somos da paz, mas não somos idiotas! A França está sendo atacada, a França deve se defender! E a França é você, sou eu, somos nós! (...) Eu odeio a guerra mas sou francês. $\mathrm{O}$ país está sendo atacado. Eles precisam de mim, eu irei à morte mas eu irei. (In: Marnat, 1986, p. 404)

\footnotetext{
${ }^{2}$ Em 1933 Ravel sentiria os primeiros sintomas de uma doença rara denominada afasia, espécie de lesão cerebral que impossibilita a expressão pela fala, pela escrita ou por sinais. Uma operação o levaria a morte em 19 de dezembro de 1937.

${ }^{3}$ A humilhante derrota francesa na Guerra Franco Prussiana e no movimento conhecido como a Comuna de 1871 - causa de inúmeras perdas humanas e territorial - desencadearia o movimento conhecido como Revanchismo. O sentimento da revanche alimentado por toda uma geração seria uma das causas que levaria a França lutar contra a Alemanha durante os anos da Primeira Grande Guerra.
} 
No momento da declaração da guerra, Maurice Ravel encontrava-se, juntamente com sua mãe, Marie Delouart (1840-1917), no balneário de Saint Jean de Luz, na costa basca, próximo a sua cidade natal, Ciboure. Em carta datada de 4 de agosto de 1914, destinada ao amigo Maurice Delage ${ }^{4}$, esta realidade lhe é sensível pela primeira vez:

Meu caro, escreva-me o mais rápido possível, se você receber esta carta, para que eu sinta a presença de um amigo. Existem aqui várias pessoas pelas quais eu sinto uma grande simpatia. Mas não é isso... Se você soubesse o quanto eu sofro!...Desde esta manhã a mesma ideia, terrível, criminosa...deixar minha pobre e velha mamãe seria matá-la certamente. Porém a pátria espera somente por mim para ser salva...[grifo meu]. Mas tudo isso são reflexões, e sinto que de hora em hora essa ideia fixa me enlouquece... e para não mais sentir isso, eu trabalho [Ravel trabalhava na composição do Trio para piano violino e violoncelo]. Sim, eu trabalho; e com uma segurança, uma lucidez de louco. Mas, ao mesmo tempo, meu lado hipócrita também trabalha, e repentinamente, me vejo a soluçar sobre os bemóis!

Naturalmente, quando desço, e que me encontro diante de minha pobre mamãe, preciso demonstrar um ar calmo, se não engraçado... será que poderei continuar? Já são 4 dias que isso dura, desde o tocsin ${ }^{5} \ldots$

Escreva logo, meu amigo, eu vos suplico.

Afetuosamente

Maurice Ravel (Orenstein, 1989, p. $140^{6}$ )

A correspondência de Ravel durante o período da guerra é intensa e nos permite ter uma ideia precisa da situação neste início de conflito, longe dos campos de batalha, porém em uma conturbada atmosfera em que todas as províncias francesas viveram pela falta de informação. Assim sendo, as “cartas de

\footnotetext{
${ }^{4}$ O compositor Maurice Delage (1879-1961) foi um dos raros alunos de Ravel.

${ }^{5}$ Sinal sonoro para avisar de acontecimento repentino e perigoso.

${ }^{6}$ Esta carta também foi transcrita em Ravel au miroir de ses lettres (CHALUPT, 1956, p.113).
} 
guerra" escritas pelo compositor testemunham, todas elas, um espírito bem diferente das correspondências trocadas em outro momento de sua vida. Percebese a dúvida sobre a veracidade das notícias que recebia, a necessidade de notícias dos amigos engajados ou não e o respeito pelo adversário (jamais empregará o termo pejorativo boche, tão usado pelo compositor Claude Debussy quando se referia aos alemães). A linguagem usada nas cartas endereçadas a pessoas próximas a ele é ainda mais informal, notando-se a necessidade do compositor em dividir os momentos de angústia durante um período de tantos conflitos externos e internos, o que nos permite conhecê-lo intimamente, como em um diário. O amigo Roland Manuel observou: Escritor até então negligente, a guerra e a separação dos amigos irá obrigá-lo a confiar ao papel sentimentos e emoções que sua boca jamais formulou. (In: Marnat, 1986, p. 405)

Quatro dias após a carta citada anteriormente, Ravel escreve ao irmão Éduard e demonstra sua preocupação pelo momento em que vive, pelo seu trabalho, pelos amigos, pela mãe e a decisão de alistar-se:

Caro Éduard,

Hoje - 8 de agosto - ainda não temos notícias suas. E provavelmente nos escreveu há muito tempo Penso que tenha novidades do Sr. Pawloski, que me permitiu passar Avenue Carnot e te telefonar a Levallois.

Nossa posição não é nada engraçada. Restam 10 francos. Durand [sua casa editora] deve estar fechada. As sociedades dos autores também.

A maioria dos amigos, os Piot, Laurencie, Benois, Pawloski estão ou estarão nessa mesma situação pecuniária. Mas não levam isso tão a sério. Existem preocupações piores. Eu sofri durante 4 dias, desde o "tocsin", como jamais. E como sentia que ficaria louco, tomei a decisão mais sábia: vou me alistar [grifo meu]. Já pensei em todos os motivos que você poderia me objetar. Nossa pobre mamãe, sobretudo... Mas se eu ficar louco, ou ficar doente do coração, seria ainda mais triste. (...) Bem entendido, nossa pobre mamãe ignora tudo isso. Quando me escrever sobre esse assunto ou sobre outros que possam preocupá-la, escreva tudo isso à parte, e coloque em um envelope normal, não escrito de sua mão. Ainda melhor, escreva duas cartas, uma oficial, e outra...oficiosa. 
Assim que receber esta carta, vá a Sociedade dos autores, 10 rue Chaptal, e a dos Autores dramáticos, rue Henner, e pergunte se tenho algo a receber. Em anexo uma autorização. Vá também na casa de Durand, e fale sobre minha posição, que estou terminando o Trio e que provavelmente partirei.

Nos telegrafe sobre notícias suas, se possível.

Abraçamos-te

Maurice (Orenstein, 1989, p. 140)

Em carta endereçada ao amigo Cipa Godebski ${ }^{7}$ em 20 de agosto de 1914, nota-se o sentimento obsessivo do compositor pela defesa de seu país, o reconhecimento do inimigo alemão e também a extrema preocupação pela mãe, com a qual vivia. Nota-se igualmente, em quase todas as suas "cartas de guerra”, a presença desta figura materna à qual se dedicou exclusivamente.

Velho,

No dia seguinte em que vos escrevi, pedi minha certidão de nascimento, pense, somente uma ponte para atravessar! A vossa exceção, todos, mobilizados, alistados, inclusive um oficial, me censuraram. Você me conhece o suficiente para saber que estas censuras não podem influenciar sobre minha decisão: eu partirei (se me quiserem), porque tenho vontade de partir. Somente - cada um tem seus defeitos; o meu é agir em plena consciência [grifo meu] - eu sei que cometo um crime, e não é necessário que todos me confirmem.

O que me fez... hesitar, como vocês dizem, durante dois dias.

Você nunca hesita... porém, meu caro, nossa situação é bem diferente! Se lhe fosse permitido partir, você deixaria somente uma jovem mulher e as crianças que podem ficar sem você. Valery Larbaud deixa uma mãe ainda jovem. Mas minha mãe é uma pobre mulher velha que nem religião, nem

${ }^{7}$ Cipa Godebski (1864-1937) e sua esposa Ida (1872-1935) dois dos amigos mais íntimos do compositor e aos quais dedica sua Sonatine (1905) para piano solo. Segundo Orenstein, estão catalogadas 250 cartas de Ravel endereçadas aos diversos membros da família Godebski. 
princípios a poderiam sustentar, e cujo único ideal sempre foi o amor de seu marido e de seus filhos, e que não teve vergonha de conservar o que the resta. Uma espécie de monstro, não é mesmo? É, existem muitos, desses tipos de monstros! E aquele você sabe quanto eu amo [referindo-se à mãe]. Não sei bem como ela suportaria o que escondo, o alistamento de meu irmão como automobilista; mas sei, e tenho certeza do que acontecerá quando ela souber que a deixaremos. Não terá nem mesmo do que morrer de fome.

É por isso que tomei uma segunda decisão, no caso em que volte vivo. Esta decisão é tão irrevogável quanto a outra.

Então: Viva a França! E sobretudo: abaixo a Alemanha e a Áustria! [grifo meu] Ou ao que estas duas nações representam nesse momento. E de todo o coração: viva a Internacional ${ }^{8}$ e a Paz! È por isso que eu parto, assim como Hervé, cuja ação parece vos ter surpreendido.

Afetuosamente a vocês dois

Maurice Ravel

E por que não: viva a Polônia! (Orenstein, 1989, p. 141)

Tomada a decisão de alistar-se, Ravel dirige-se à caserna de Bayonne, próximo de onde se encontrava, para submeter-se aos vários exames médicos exigidos para o alistamento. O compositor será impedido de participar de seu projeto patriótico e é recusado pela sua estatura, 1,57 metros e seu peso, 48 quilos, sendo que o mínimo exigido era 50 quilos. Em 1895, aos 20 anos, ele já teria sido dispensado do serviço militar pelo mesmo motivo. Em carta de 8 de setembro, Ravel anuncia o resultado a amiga Ida Godebska; trata-se de uma longa carta, essencial para compreendermos suas preocupações musicais, militares e civis do momento:

Cara amiga, como você previa, minha aventura terminou da forma mais ridícula: não me quiseram porque me faltam dois $\mathrm{Kg}$. Antes de me dirigir a

\footnotetext{
${ }^{8}$ Hino revolucionário escrito por Eugène Pottier em 1871.
} 
Bayonne, eu passei um mês trabalhando da manhã à noite sem ter tempo para tomar um banho de mar. Eu queria terminar meu Trio que já até tratei de obra póstuma. Isso não quer dizer que prodigalizei o gênio mas que a ordem de meu manuscrito e das notas que se relacionam permitiriam qualquer um de corrigir as provas. Tudo isso é inútil: e resultará somente em mais um Trio.

Sem contar os dois dias de febre após minha volta de Bayonne. Eis me aqui sem ação. Esperava dedicar-me aos feridos transportados a Saint Jean de Luz. Um banqueiro judeu doou dez mil francos à cidade para os soldados. Depois colocou no cassino [Segundo Plotto o cassino da cidade foi transformado em hospital para receber os soldados feridos] várias mulheres e jovens, ociosos desde o fechamento do golf, para passar o tempo com os feridos, causando uma certa confusão e desencorajando a melhor das boas intenções. Felizmente desconfiaram e enviaram aqui somente casos não muito graves. De resto a Bayonne tiveram todo o cuidado do mundo em dispensar uma grande quantidade de mulheres da Cruz Vermelha que doaram dinheiro para atrapalhar os hospitais, indignando-se para que lavassem os pés dos soldados, defendendo-se sob a ignorância para evitar os tratamentos e reclamando pelo fato de não terem instalado um salão de chá. (...)

Eu passo meu tempo a levantar a moral de alguns nacionalistas que escolheram o momento para fazer política e duvidar de tudo para não dizer mais. Estou muito preocupado com Eduard [seu irmão]. Em sua última carta ele esperava ser aceito [nas armas]. Há quinze dias não tenho nenhuma notícia sua (...).(Chalupt, 1956, p. 116)

O Trio para piano, violino e violoncelo, aqui mencionado, se destaca pela importância, musical e histórica, no sentido de representar uma referencia dentro do movimento nacionalista francês. A obra foi inteiramente composta em SaintJean de Luz / Ciboure terra natal do compositor, as vésperas da declaração da Guerra. Saint-Jean de Luz / Ciboure faz parte da região basca (noroeste da França, fronteira com a Espanha), de forte influência hispânica e, a Terceira República Francesa, como causa do movimento revanchista, pós Guerra Franco-Prussiana e Comuna de 1871, tornaria obrigatório o ensinamento das canções de todas as províncias da França, numa forma de resgatar e valorizar o folclore nacional. Nesse sentido, para a composição do seu Trio, Ravel vai usar, em busca de suas origens, elementos do folclore basco para a composição desta obra. O Trio é composto de quatro movimentos: Modéré, Pantoum - Assez vif, Passacaille - Très 
large e Final - Animé. Nenhum tema comum nestes quatro movimentos independentes, de grande clareza e rigor formal, características comum entre as obras compostas durante os anos da guerra.

Ravel não aceita o fato de ter sido recusado as armas e relata novamente sobre o seu fracasso em participar, como definiu, desta esplêndida luta, em carta datada do dia 21 de setembro de 1914, endereçada à Sra. Casella ${ }^{9}$, na qual mais uma vez escreve sobre suas composições atuais, sobre o irmão, sobre os amigos e sobre uma nova oportunidade para ser aceito como soldado.

Sua carta me encontrou ainda em Saint Jean de Luz. A análise do meu Trio, as notas para a correção das provas e a execução em caso de minha ausência; tudo isso é inútil: me faltam dois quilos para ter o direito de participar a esta esplêndida luta [grifo meu]. Tenho somente uma esperança, que no próximo exame que irei passar, eles acabem por perceber o charme de minha anatomia.

Meu irmão teve mais chance: ele é automobilista no $19^{\circ}$ esquadrão do trem. Ele tem um belo uniforme e uma Panhard novinha. Essas informações obtive da Sra. Delage e de Pierre Haour. Quanto a Éduard, ele não nos escreve, ou suas cartas não chegam até nós. Eu sei que o padre Petit cuida do forte de Antibes, que Sordes está em Verdun tranquilo... que Schmitt se aborrece em Toul, a bocejar para os aeroplanos que passam muito alto, que Delage espera por estar a Bordeaux, com a Sra. Noailles, Le Bargy, Maurice Rostand e alguns parisienses do mesmo tipo. Eu pensei ter entendido que Cocteau também dirigia as tropas do parque de Bologne, relendo Virgile. Haour não pode reencontrar seu novo camarada. Nenhuma novidade de Stravinski [durante a Guerra o compositor se isolaria na Suíça]. A Suíça é um país longínquo, neste momento. Há quase um mês que espero por uma resposta de meus parentes de Genebra. Não tenho mais coragem de me colocar ao trabalho, tanto que as duas obras que comecei e às quais eu deveria me atrelar após o Trio faltam de propósito: 1) La Cloche engloutie em colaboração com Gerhard Hauptmann ${ }^{10}$; 2) um poema sinfônico que começou bem: Wien ${ }^{11}$ !!! Sem condições de chamar isso de Petrogard.... (Chalupt, 1956, p. 117)

\footnotetext{
${ }^{9}$ Esposa do célebre pianista Alfredo Casella, amigos de Ravel.

${ }^{10}$ Escritor alemão, dedicou-se a romances e obras dramáticas, recebeu o Prêmio Nobel de Literatura em 1912. Autor de La Cloche engloutie, obra mística e simbólica.

${ }^{11}$ Esta obra foi escrita sob o título de La Valse. Somente após a guerra Ravel concluiria essa obra, dedicando-se a ela de dezembro de 1919 a abril de 1920.
} 
De acordo com carta escrita cinco dias mais tarde ao amigo Roland Manuel, Ravel reencontra coragem e inspiração para compor e se pronuncia sobre a criação da suíte Le Tombeau de Couperin. Novamente relata sua frustração em não ser aceito pelo exército, deixando claro que esse "imprevisto" não o fará desistir de seu projeto patriótico.

Meu caro amigo,

Já há algum tempo me perguntava o que aconteceu com você em meio a todos esses acontecimentos. E não tinha como me informar, desconhecendo o endereço de sua família.

Obrigado por ter me tranquilizado e dado notícias sobre meu irmão, o qual decidiu vos escrever. Ele enfim iniciou seu serviço, que segundo ele é horrível. Eu acho que não o enviaram para procurar miosótis no campo de batalha.

Como você pode imaginar, somos terrivelmente tranquilos, aqui. Eu nunca trabalhei tanto, e tão rapidamente como neste verão, sobretudo desde a mobilização. Em 5 semanas, forneci o trabalho de 5 meses. Eu quis terminar meu Trio antes de me alistar, e tive a decepção de ter sido julgado 2 quilos mais leve. Espero agora pelo exame geral dos reformados, e se ainda não conseguir, vou tramar algo assim que voltar de Paris. Eles acabarão sensibilizando-se pelo charme de minha anatomia. Esta esperança me dá coragem para me turbinar [termo usado por ele]. Vou iniciar uma suíte de peças para piano [referindo-se ao Tombeau], sendo obrigado a interromper duas obras importantes, mas que faltavam um pouco de propósito: La Cloche engloutie em colaboração com Gerhard Hauptmann e um poema sinfônico: Wien !!! (Orenstein, 1989, p. 143)

A suíte Le Tombeau de Couperin, iniciada em julho de 1914 e concluída somente em novembro de 1917, foi escrita segundo a forma do século XVIII, e composta por seis peças dedicadas, cada uma delas, a um amigo que, assim como Ravel, se engajaria pela defesa da França durante a Primeira Grande Guerra deixando, entretanto, suas vidas nos campos de batalha. A suíte Le Tombeau de Couperin não constituiu apenas uma homenagem a François Couperin, mas a toda a música francesa do século XVIII, mas também como um adeus aos amigos desaparecidos na linha de frente. As seis peças que compõem a Suíte foram 
inspiradas em formas musicais do século XVIII e estão assim organizadas: Prélude dedicado ao amigo e colaborador Jacques Charlot; Fugue dedicada ao amigo Jean Crouppi; Forlane dedicada ao amigo Gabriel Deluc; Rigaudon, os irmãos Pierre e Pascal Gaudin foram os homenageados; Menuet dedicado ao amigo Jean Dreyfus; e Toccata, dedicada ao amigo Joseph de Marliave. A busca por elementos do passado se justifica, uma vez que os compositores da geração revanchista, como forma de salvaguardar a música francesa, buscariam reviver o significativo século XVIII francês - esquecido durante o século XIX, o qual seria dominando por compositores germânicos - e inspirar-se-iam nos mestres franceses do passado. Assim, o Tombeau de Maurice Ravel vem prestar uma homenagem aos amigos, cidadãos da Terceira República Revanchista que, como ele, tomados pelo sentimento de proteção a pátria, lutaram nos campos de batalha e, também, como teria declarado em seu esboço autobiográfico, homenagear não só François Couperin, mas toda a música francesa do século XVIII (Orenstein, 1989, p. 46).

Antes de voltar a Paris, para dar continuidade ao seu plano de alistar-se, Ravel escreve uma última carta de Saint Jean de Luz, endereçada ao amigo Roland Manuel, em $1^{\circ}$ de outubro de 1914 . Nesta carta o compositor confirma todos os acontecimentos relatados em sua correspondência anterior: sobre a ideia fixa em alistar-se, a frustração por não ter sido aceito nas armas francesas, sua generosidade em voluntariamente cuidar dos soldados feridos, o relato e a falta de notícias dos amigos, sobre o irmão e as dificuldades em dar continuidade as suas composições. Pela sua importância, transcrevo essa carta:

Mas eu sei bem, meu caro amigo, que trabalho para a pátria fazendo música! [grifo meu] Disseram-me o suficiente, há dois meses, para me convencer; primeiro para impedir de me apresentar, e depois para me consolar de meu fracasso. Não me impediram, e não me consolo.

Será necessário esperar, para agir, (...). 
Enfim, eu faço um trio, como o pobre Magnard ${ }^{12}$ : é sempre um começo.

Eu cuido também dos feridos todas as semanas, o que é muito desgastante: é inaudito o número, senão a variedade das necessidades que podem ter 40 homens no decorrer de uma noite!

Também faço música: impossível continuar Zazpiac-Bat ${ }^{13}$, pois os documentos ficaram em Paris. Delicado trabalhar La Cloche engloutie - esta vez, acredito que ela está bem -, e de acabar Wien, poema sinfônico. Esperando retomar meu velho projeto de interior, de Maeterlinck, eu começo duas séries de peças para piano: $1^{\circ}$ ) uma suíte francesa - não, não é o que você pensa: A Marseillaise não aparecerá, e haverá uma forlane, uma gigue; portanto sem tango. $2^{\circ}$ ) Uma Nuit romantique, com spleen ${ }^{14}$, caça infernal, nona maldita, etc ${ }^{15}$.

Vossa carta caiu bem: estava para escrever a Sra. Vossa mãe uma carta que provavelmente nunca teria chegado. É desolador enviar correspondências no vazio, e portanto vou começar a fazê-lo. Não posso mais ficar sem notícias dos amigos. Algumas vezes, recebemos notícias terríveis, indiretamente, que são desmentidas 2 dias depois. É assim que soube da morte do capitão Marliave, e que não ouso escrever à sua esposa ${ }^{16}$, e mais do que Vaudoyer, que perdeu seu jovem irmão, dizem.

Delage recebeu minha carta do 28? Ele está em Bordeaux? Quanto a meu irmão, nada mais. É verdade que em tempos de paz ele também escrevia pouco.

12 O compositor Albéric Magnard (1865-1914) publicou um trio em 1916. Morreu tragicamente em 3 de setembro de 1914 defendendo sua casa, incendiada por soldados alemães.

13 Obra abandonada em 1914, idealizada para piano e orquestra e inspirada em temas bascos.

${ }^{14}$ Termo inglês que quer dizer tristeza doentia.

${ }^{15}$ De todos esses projetos, somente dois foram concluídos, a Suíte Francesa (Le Tombeau de Couperin) e La Valse, ainda chamada de Wien. Ravel cita o tango, alusão ao bispo de Paris, que havia declarado que esta nova dança, extremamente popular, era lasciva e ofendia a moralidade (Laloy: 1914, p.47).

${ }^{16}$ A pianista Marguerite Long (1874-1966) realiza a primeira audição do Tombeau de Couperin e do Concerto em Sol, dedicado a ela. A Toccata do Tombeau é dedicada à memória do capitão Joseph de Marliave, seu esposo, importante musicólogo, autor de um estudo sobre os quartetos de Beethoven. Esta publicação contou com uma introdução realizada pelo compositor Gabriel Fauré. 
Não temos mais Cécil Sorel ${ }^{17}$. Nouguès ele mesmo nos deixou...

Escreva logo. Pensei entender que seus pais estavam com você. Passe a eles meus cumprimentos e cordialmente seu

Maurice Ravel (Orenstein, 1989, p. 144)

Nesse momento a França contava os seus mortos, após a Batalha de Marne $^{18}$, que arrasou toda uma geração de franceses, entre estes um grande número de artistas que se encontravam lutando no fronte. A causa desta conhecida batalha seria uma contra-ofensiva francesa realizada com o objetivo de conter o avanço alemão, tão temido desde a ação da Comuna em 1871, que tentava mais uma vez se aproximar de Paris. Um balanço dos artistas mortos neste e nos vários combates seria publicado regularmente com a criação do jornal La Musique pendant la Guerre ${ }^{19}$. Inicialmente mensal, este jornal de índole nacionalista tinha como objetivo constituir um documento histórico com a colaboração dos vários músicos franceses, documentando todos os acontecimentos musicais durante o conflito e alimentando o sentimento de repulsa em relação ao inimigo alemão. O primeiro número deste importante documento foi colocado em circulação em 10 de outubro de 1915. Segue o primeiro balanço das baixas nos campos de batalha publicado no primeiro número do jornal em questão.

\footnotetext{
${ }^{17}$ Célebre atriz (1873-1966).

${ }^{18}$ Esta batalha aconteceu de 6 a 9 de setembro de 1914.

${ }^{19} \mathrm{O}$ estudo deste jornal de índole nacionalista faz parte de minha atual pesquisa, em nível de Pós-Doutorado intitulada As Sociedades Musicais Francesas do início do século XX: ideologias e consequências. Societé Nationale de Musique - SNM, Schola Cantorum, Societé Musicale Independente - SMI, Journal de la Musique pendant la Guerre, Festival de La Musique Française e Ligue Nationale pour la défense de la Musique française. A pesquisa está sediada no Departamento de Música da ECA-USP, e conta com o apoio da FAPESP.
} 
Figura 1 - La Musique Pendant la Guerre. Paris: Comptoir Géneral de Musique, n. 1 - 10/10/1915, p. 14. BNF - Bp 106.

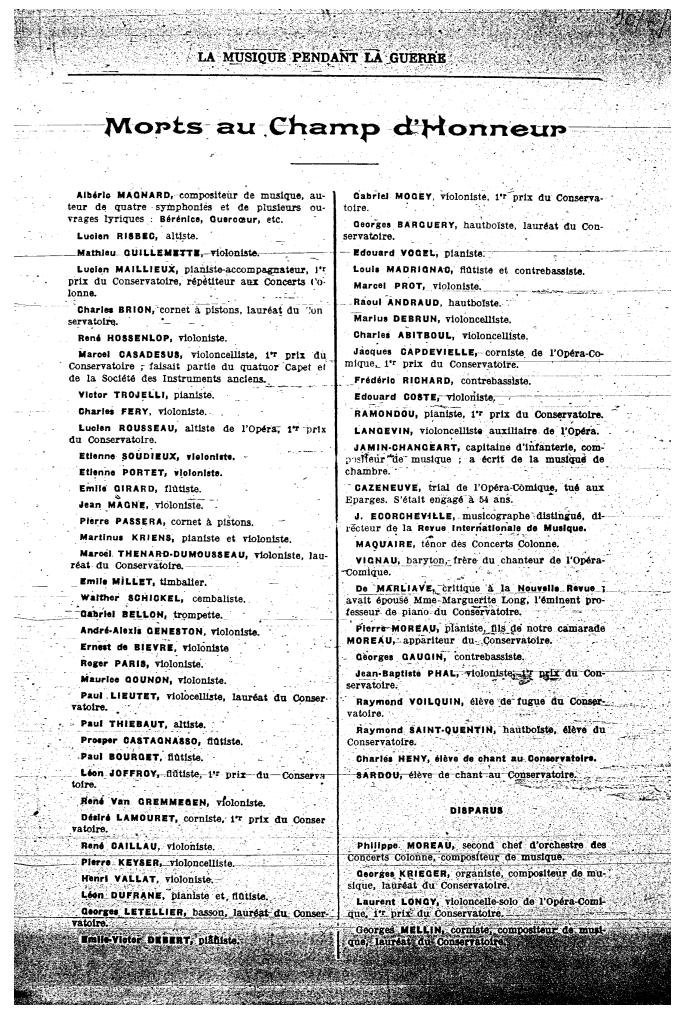

Em outubro de 1914, Ravel, em companhia de sua mãe, volta a Paris e como era previsto faz uma nova tentativa para ser incorporado, desta vez na aviação. Dirige-se então, segundo seus biógrafos Marcel Marnat e Étienne Rousseau-Plotto, ao matemático (especialista de problemas aeronáutica) e deputado republicano socialista Paul Painlevé, para ser aceito na aviação, estimando que seu peso seria uma vantagem. Enquanto aguarda, escreve sua única obra para coro misto a cappela, as Trois chansons pour choeur mixte sans accompagnement. Ele mesmo escreve os poemas, nos quais descreve os horrores da guerra, e ao mesmo tempo se apresenta como uma obra patriótica ao evocar as cores da bandeira francesa. A iniciativa de escrever os textos para suas chansons, transmite a necessidade do compositor de se expressar, não só com a sua música mas também fazendo o uso da palavra, descrevendo de forma 
subjetiva seus sentimentos em relação aos horrores da guerra e confirmar assim o envolvimento com os ideais de nacionalismo e o sentimento de patriotismo. As Trois Chansons pour Choeur mixte sans accompagnement, foram compostas entre dezembro de 1914 e fevereiro de 1915. Ravel dedica cada uma delas a um possível intercessor de seu projeto patriótico de participar como soldado de guerra: a primeira a Tristan Klingsor; a segunda a Paul Painlevé e a terceira a Sophie Clémenceau. As chansons que compõem esta importante obra são: Nicollette (Lá menor, finalizando Maior), Trois beaux oiseaux du Paradis (Fá menor) e Ronde (Lá Maior). Os textos parodiam com extremo requinte as chansons francesas da Renascença e do folclore basco e infantil (primeira e terceira), nos quais esboça - conforme mencionado igualmente para as outras duas obras do período - uma volta ao passado que a Terceira República francesa idealizava.

Certamente a notícia da morte de seus primeiros amigos e de numerosos artistas inspiraria o texto da segunda canção, Trois beaux oiseaux du Paradis, uma das páginas mais comoventes do compositor. O poema nos fala do horror da guerra e ao mesmo tempo se apresenta como uma obra patriótica ao evocar as cores da bandeira francesa para cada um dos Três belos pássaros do Paraíso: "o primeiro era mais azul que o céu", "o segundo era cor de neve" e "o terceiro vermelho vivo". Pela importância do texto no sentido do comprometimento de Ravel com a causa da guerra, transcrevo e traduzo o poema da segunda canção, Trois beaux oiseaux du Paradis:

Trois beaux oiseaux du Paradis,

(Mon ami z-il est à la guerre)

Trois beaux oiseaux du Paradis,

Ont passé par ici.

Le premier était plus beau que le ciel, (Mon ami z-il est à la guerre)

Le second était couleur de neige

Le troisième rouge vermeil.
Três belos pássaros do Paraíso.

(Meu amigo z está na guerra)

Três belos pássaros do Paraíso.

Passaram por aqui.

O primeiro era mais azul que o céu, (Meu amigo z está na guerra)

O segundo era cor de neve

O terceiro vermelho vivo. 
Beaux oiselets du Paradis,

(Mon ami z-il est à la guerre)

Beaux oiselets du Paradis,

Qu'apportez par ici?

J'apporte un regard couleur d'azur,

(Ton ami z-il est à la guerre)

Et sur beau front couleur de neige,

Un baiser dois mettre, encor plus pur.

Oiseau vermeil du Paradis,

(Mon ami z-il est à la guerre)

Oiseau vermeil du Paradis,

Que portez-vous ici?

Un joli coeur tout cramoisi

(Ton ami z-il est à la guerre)...

Ah! Je sens mon coeur qui froidit...

Emportez-le aussi.
Belos passarinhos do Paraíso,

(Meu amigo z está na guerra)

Belos passarinhos do Paraíso

O que trazem por aqui?

Eu trago um olhar na cor azul,

(Teu amigo z está na guerra)

E sobre belo fronte cor de neve,

Um beijo, ainda mais puro.

Pássaro vermelho do paraíso.

(Meu amigo z está na guerra)

Pássaro vermelho do paraíso,

O que você traz aqui?

Um belo coração carmesin ${ }^{20}$

(Teu amigo z está na guerra)...

Ah! Eu sinto meu coração esfriar...

Leve-o também.

Simultaneamente, Ravel continua sua luta pessoal para se fazer incorporar, e graças ao amigo Tristan de Klingsor, dedicatário da primeira das Trois chansons pour choeur mixte a cappela, que o coloca em contato com militares importantes, o compositor será incorporado, em 10 de março de 1915. não na aviação como pretendia, mas como condutor de caminhões. Segue cópia do certificado da primeira dispensa do serviço militar de Ravel (7 de fevereiro de 1894), onde podemos confirmar o carimbo da sessão do conselho de revisão de 10 de março de 1915 que o aprova para o serviço auxiliar.

${ }^{20}$ Vermelho vivo. 
Figura 2 - BnF. Mu. L.a. Ravel 169 - vol. 89.

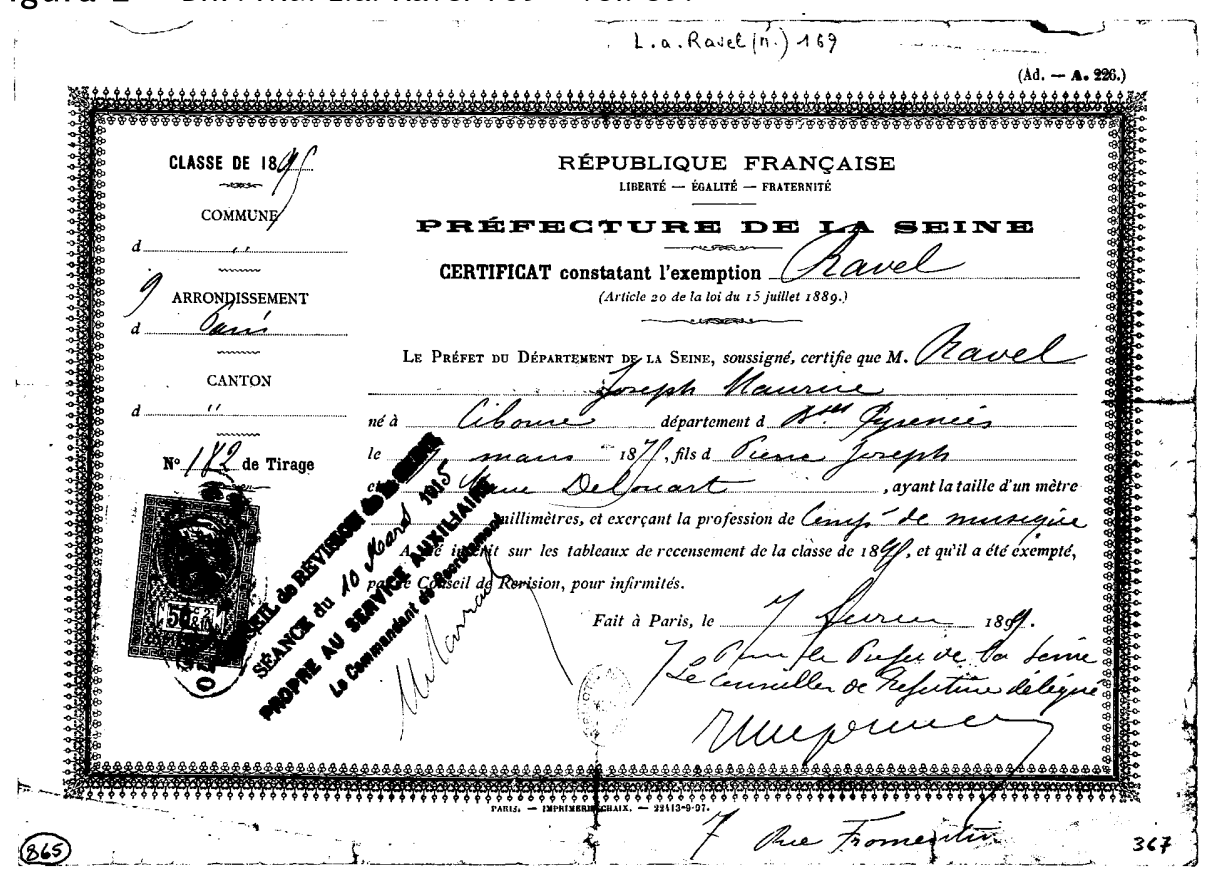

De acordo com a correspondência do início de março de 1916, ou seja, quase dois anos após sua decisão em participar ativamente como soldado e as várias tentativas para ser aceito, Ravel é enviado ao nordeste francês, próximo a Verdum, onde acontecia a guerra de trincheiras. Sua principal função era o carregamento e transporte de material de guerra. Durante o período em que atuou como soldado, o compositor relatou, em suas cartas, a realidade da guerra. As duas primeiras cartas escritas do front pelo compositor, datadas de 19 de março de 1916, foram endereçadas à sua mãe e ao amigo Jean Marnold. Nelas Ravel escreve sobre suas primeiras impressões, agora como soldado. Na carta endereçada à mãe, Ravel omite certos detalhes, por esse motivo traduzo e transcrevo trecho da carta escrita ao amigo, na qual relata com mais detalhes sobre sua realidade e expectativas. As cartas escritas do front serão precedidas pela seguinte indicação: 
Conducteur Ravel

Convois automobile

Section T. M. 171

Par B. C. M. Paris

Caro amigo,

Eis-me aqui há uma semana "no front". É ainda longe da realidade, mas é ainda mais longe de Paris. Moralmente sinto muito próximo. Os vôos dos aviões, os comboios carregados de homens, as flechas indicadoras, tudo se dirige para...lá, em direção à gigantesca batalha. Os camaradas voltam a todo o momento.

Todas as noites a sirene da estação, a da usina anunciam os Zeppelins. Quando a região é ameaçada diretamente, os clarões soam o "garde-à-vous" [expressão no sentido de se protegerem].

Não estou infeliz apesar das severas regras e da falta de conforto, para não dizer mais, do dormitório. A alimentação é boa e aproveito. Quase que imediatamente recebi um grande caminhão que andava somente sobre três patas e que recolheram no dia seguinte. (...) Deram-me uma caminhonete capaz de andar sobre estas estradas. Prometeram-me missões interessantes. (...) (BNF. Mu. L.a. Ravel vol. 89, 170)

Toda correspondência enviada do fronte era inspecionada, a lei militar francesa proibia aos soldados citar em suas cartas o local preciso onde se encontravam; por esse motivo, em várias cartas enviadas como soldado de guerra, Ravel deixa supor sua localização, como podemos perceber na carta citada anteriormente ${ }^{21}$. Os poilus, como ficaram conhecidos os soldados franceses, devido à pele de animal que usavam para se proteger do frio, recebiam uma espécie de ficha, do tamanho de uma carta postal onde deveriam se identificar,

${ }^{21}$ Ou ainda: (...). Estando alguns dias de serviço em ... . eu vinha jantar com (...) (Orenstein, 1986, p. 148), (...) A cada curva, é a mesma indicação: V..... e uma flecha (...) (Orenstein, 1986, p. 150) ou (...). Outro dia me confiaram uma dessas "missões interessantes", das quais você me aconselha desconfiar. Eu deveria ir a X... para levar um carro requisitado (...) (Orenstein, 1986, p. 151). 
tendo o espaço do verso para escrever. Este espaço vinha precedido do seguinte texto:

Esta carta deve ser entregue ao "vaguemestre"22. Ela não pode conter nenhuma indicação do local de envio nem informações sobre as operações militares passadas ou futuras. Se esse fato for notado, ela não será transmitida. (BNF. Mu. L.a. Ravel vol. 89, correspondência enviada do fronte)

Sobre o texto das cartas de Ravel enviadas do fronte, foi notado um carimbo de inspeção autorizando o envio das mesmas. A Bibliothèque Nationale de France não permitiu a reprodução destes documentos ${ }^{23}$.

Ainda a Jean Marnold, quinze dias depois da carta mencionada anteriormente, Ravel divide com o amigo um dos vários momentos de solidão e de questionamentos sobre a guerra:

Obrigado, meu caro amigo, por sua carta - se você soubesse a alegria com a qual a recebemos! Obrigada pelas verdadeiras notícias que me dá a respeito de mamãe.(...) Vi algo alucinante: uma cidade de pesadelo, horrivelmente deserta, e muda. Não é o fracasso lá do alto, nem os pequenos balões de fumaça branca que se alinham no puro céu; não é o duelo formidável e invisível que é angustiante, é de sentir-se só no centro desta cidade que dorme um sono sinistro, sob a luz resplandecente de um belo dia de verão. Verei sem dúvida as coisas mais terríveis, mais repugnantes; nunca pensei sentir algo de mais profundo, de mais estranho do que esta espécie de terror surdo. (...) (Orenstein, 1989, p. 151)

Durante suas idas e vindas de Verdum, um acidente o imobiliza por um mês, para o conserto de seu caminhão. Em uma carta enviada à Sra. Fernand Dreyfus em 10 de maio, percebemos passado o entusiasmo inicial e a realidade da guerra se faz presente:

\footnotetext{
${ }^{22}$ Militar responsável pela fiscalização de toda correspondência enviada do fronte.

${ }^{23}$ De acordo com as informações da Biblioteca Nacional da França, setenta anos da data de morte do compositor mais os anos de guerra multiplicados por dois, é a lei que proíbe a reprodução dos documentos, manuscritos musicais e correspondências de todos os compositores franceses.
} 
Minha vida de homem da montanha se organiza. "Você estará aqui até o final da guerra": esta brincadeira que parecia atraente no início, começa a perder o seu frescor. Eu me vejo ainda fumando um cigarro em uma outra floresta mais calma. O cortejo precipitado de quatro macas levando os cadáveres de marroquinos, entre os quais um sem a cabeça. Penso que ainda teremos muitos anos pela frente. E o que sinto nesse momento não é horror, medo, mas ao contrário, o desejo de que meu caminhão seja consertado.

Eu sou pacífico, nunca fui corajoso. Mas eu tive a curiosidade da aventura. Ela tem um sabor que se torna necessário. O que farei, o que farão muitos outros após a guerra? (In: Marnat, 1986, p. 412)

Esse momento de pausa forçada leva o compositor a se questionar sobre sua vocação de soldado, conforme carta enviada ao Major Blondel em 27 de maio de 1916. Neste depoimento é possível confirmar a que ponto Ravel arriscou a sua vida para realizar o seu projeto patriótico. O manuscrito deste importante documento encontra-se na Biblioteca Nacional da França e não foi publicada nos trabalhos referentes a correspondência do compositor. É uma longa carta, quatro páginas em que Ravel expõe os perigos de suas missões e admite não ser essa a sua vocação. Traduzo e transcrevo trecho deste documento :

Senhor Major e caro colega,

como pode ver, ainda estou vivo. Ainda tem momentos onde isso me espanta. Devo primeiramente me desculpar pelo meu longo silêncio. Durante uma semana, eu rodei dia e noite - sem luz - sobre estradas inacreditáveis, quase sempre com uma carga duas vezes mais pesada para minha caminhonete. E apesar disso, não podia demorar, pois tudo isso acontecia sobre o obus. Eu não acredito que um automobilista possa ver tanto em tão poucos dias. Uma destas, um austríaco, me envia no meio da cara os resíduos de sua poeira. Adelaide e eu - Adelaide, é minha caminhonete - escapamos aos shrapnells; mas a coitada não aguentou e, após quase me abandonar em uma zona perigosa, onde era proibido estacionar, ela deixa cair de desespero uma de suas rodas, em uma floresta onde fiz o Robinson durante 10 dias, esperando que viessem me salvar...Gostaria sobretudo de agradecer, profundamente, por, mesmo contra sua vontade, fazer o possível em facilitar uma vocação a qual eu não era destinado, sem dúvida, pois, há 2 anos, tudo se opôs: amigos, acontecimentos, saúde. (...) (BnF. Mu. L.a. Ravel, 171 - vol 89) 
Durante os onze meses que permaneceu no front, o compositor escreve quase que diariamente, e nos numerosos períodos de repouso, devido sua fragilidade física, coloca no papel suas angústias e reflexões, como nesta datada do dia 25 de maio de 1916 e endereçada ao amigo Jean Marnold:

(...) O que fazer agora? Se repassar uma consulta diante de um major mais sério, serei declarado inapto para o automobilismo e me trancarão em um escritório. Você compreende que eu prefiro deixar as coisas andarem sozinhas. Eu não serei o único que a guerra terá deixado anormal. E depois (...) eu sei que tudo isso começou no dia 3 de agosto de 1914 às 3 horas da tarde. É idiota ter medo - mas eu tenho. (...) (In: Marnat, 1986, p. 413)

Nesse período Ravel obtém uma permissão para passar alguns dias em Paris, justificada pelo seu estado de saúde. Isolado de todo o meio musical e de suas composições, o compositor escreve em 4 de junho:

Eu sofro somente de uma coisa, é de não poder abraçar minha pobre mamãe, sim... Entretanto, tem outra coisa: a música. Eu pensei tê-la esquecido. Há alguns dias, ela reaparece, tirânica. Não penso em outra coisa. Tenho certeza que estaria em pleno período de produção. (In: Marnat, 1986. p. 416)

Em Paris, prepara sua resposta à Ligue Nationale pour la défense de la musique française. Liderada por Vincent d'Indy, ao lado do antigo diretor do conservatório Théodore Dubois, Camile Saint Saëns, Gustave Charpentier, Xavier Leroux e Charles Lecocq idealizaram a notícia e o estatuto de adesão de uma associação, enviada a toda comunidade musical francesa, que teria como objetivo principal militar contra todo tipo de manifestação artística pertencente aos países inimigos. Em pesquisa de campo a Biblioteca Nacional da França foi possível o acesso deste importante documento que curiosamente se encontra catalogado junto a correspondência de Maurice Ravel. Pela relevância do texto, traduzo e transcrevo a integral da notícia da Ligue Nationale pour la défense de la musique française, para que possamos entender a que ponto a guerra pôde influenciar a geração dos músicos em questão, levando ao extremo o sentimento de importantes artistas e intelectuais: 
Liga Nacional pela defesa da Música Francesa

Sua predominância na França - Sua propagação no Estrangeiro

Notícia

Em todas as esferas de atividades, a ideia fixa do triunfo da Pátria nos impõe o dever de agrupamentos e uniões.

A arte musical cuja função é econômica e social não deve ficar estranha a esta precaução de uma solidariedade ativa.

A Liga Nacional nasceu desta necessidade de ação.

Trata-se através de todos os meios de caçar, depois perseguir o inimigo; de prevenir para o futuro o retorno das infiltrações funestas.

Se não pode ser questão repudiar, para nós e os jovens, o clássico, que constitui um dos monumentos imortais da humanidade, é importante condenar ao silêncio a Alemanha moderna pangermanista.

Nosso objetivo é de nos unir e nos solidarizar, para preparar o futuro e a libertação, abandonando as pequenas querelas de companhia.

Inicialmente, a fim de afastar, indefinidamente, a execução pública de obras austro-alemães contemporâneas, não tombadas pelo domínio público, seus intérpretes, Kappelmeister e virtuoses, suas operetas vienenses, filmes cinematográficos que poluem, seus discos fonográficos mais ou menos maquiados, de desmascarar suas manobras, os pseudônimos dos atores de canções que, mesmo atualmente, enganam a Censura; de vigiar para que o inimigo não passe nossa fronteira.

A fim de assegurar o desenvolvimento de nossa música; de vigiar pelos interesses profissionais de nossos compatriotas; de conservar nosso patrimônio nacional, sem distinção de gêneros e escolas; de trabalhar por todos os meios pela predominância, na França, de nossa arte, à venda fácil das edições e audições públicas; de criar bases de intercâmbio com as nações aliadas - e acolhendo na medida do possível a arte destes. 
Nossos meios de ação, dependendo das circunstâncias, serão múltiplas: coalizões, controles, propagandas, intervenções nos poderes públicos, reformas nos livros e regulamentos de nossas escolas, interdições, ações comuns em vistas da edição francesa, luta contra os cartéis suspeitos, subvenções, descentralizações, etc, tudo o que sugerirá a vontade durável de quebrar as revanches inimigas.

A Liga foi constituída conforme a lei em sua assembléia de 10 de março de 1916. Sua cotização inicial é simbólica (0fr. 25 e 1 franco).

Aderir, sustentar a Liga pelo apoio do número e da vontade é fazer obra patriótica e artística. É contar também entre os quais irão querer se lembrar.

Os grandes sindicatos profissionais asseguram um apoio importante.

A liga apela à adesão de todos os Músicos e amigos da música que, no limite de suas possibilidades e, inspirando-se pelo esforço sublime de nossos irmãos sob as armas, se interessem aos destinados da arte de nossa pátria, fazendo assim ato de francês.

A Música da França aos Franceses.

Presidentes de Honra: Camille Saint-Saëns, Théodore Dubois, Gustave Charpentier.

Do Instituto: Vincent d'Indy, Xavier Leroux, Charles Lecocq. Paul Meunier, Lucien Milllevoye, deputados, presidentes de grupo parlamentar de Arte.

Secretário Jean Poueigh

(BNF. Mu. L.a. Ravel vol. 89, 188)

Em uma longa carta enviada como resposta a este convite de adesão Ravel explica suas razões pelo fato de recusar sua participação ao movimento em questão. A resposta de Ravel à Liga testemunha a sua independência intelectual e 
a sua coragem, pois o compositor toma uma posição impopular num debate explosivo e passional.

A recusa de adesão a Liga Nacional lhe custou a hostilidade de vários músicos, entre eles Vincent d’Indy e Camille Saint Saëns, envolvidos pelo sentimento de um nacionalismo radical, em nome da proteção da música francesa. Traduzo e transcrevo na íntegra a carta em que o compositor questiona a ação da Liga e surpreende pela sua lucidez e consciência artística:

Ao Comitê da Liga Nacional pela Defesa da Música Francesa

Zona das armas

7 de junho de 1916

Senhores,

Um repouso forçado me permite enfim responder ao envio da Notícia e Estatuto da Liga Nacional pela Defesa da Música Francesa, que com muito atraso chegou em minhas mãos.

Desculpem-me se não pude lhes responder antes: minhas várias transferências, meu serviço aventureiro não me permitiram tempo de lazer até então.

Desculpem-me também por não poder aderir ao vosso Estatuto. A leitura atenta desta e de vossa Notícia me obriga a recusar tal adesão.

Bem entendido, eu posso somente louvar vossa "ideia fixa do triunfo da Pátria”, que persegue a mim mesmo desde o início das hostilidades. Consequentemente, eu aprovo plenamente a "necessidade de ação" de onde nasceu a Liga Nacional. Esta necessidade de ação me é tão intensa que me fez deixar a vida civil, quando nada me obrigava.

Onde eu não posso vos seguir, é quando vocês questionam que "a função da Arte Musical é econômica e social”. Até então eu nunca havia considerado a música nem as outras artes dessa forma. 
Eu vos abandono de bom grado a estes "filmes cinematográficos", estes "discos fonográficos", estes "autores de canções". Tudo isso está em relações longínquas com a arte musical. Eu vos abandono mesmo, estas "operetas vienenses". Portanto mais musicais e de uma execução mais cuidadosa que os produtos similares aos nossos. Isso, como todo o resto, seria de domínio "econômico".

Não acredito que para a "salvaguarda do nosso patrimônio artístico nacional" seja necessário "proibir a execução pública na França das obras alemãs e austríacas contemporâneas, não tombadas pelo domínio público".

"Se não é questão de repudiar, para nós e para as jovens gerações, o clássico que constitui um dos monumentos imortais da humanidade", deve ser ainda menos questão "de afastar de nosso território, por muito tempo", as obras interessantes, chamadas talvez a constituir em seu tempo monumentos, e aos quais, aguardando, poderíamos tirar um ensinamento útil.

Seria até mesmo perigoso para os compositores franceses ignorar sistematicamente as produções de nossos camaradas estrangeiros e de formar assim uma espécie de companhia nacional: nossa arte musical, tão rica na época atual, não tardaria a degenerar, a se fechar em fórmulas banais.

Pouco me importa que o Sr. Schönberg, por exemplo, seja de nacionalidade austríaca. Ele não deixa de ser um músico de grande valor, cujas pesquisas plenas de interesse tiveram uma feliz influência sobre alguns compositores aliados, e mesmo entre nós. Estou encantado que os senhores Bartók, Kodály e discípulos sejam húngaros e o manifestem em suas obras com tanto gosto.

Na Alemanha, à parte o Sr. Strauss, vemos apenas compositores de segunda ordem, aos quais seria fácil encontrar o equivalente sem atravessar as fronteiras. Mas é possível que logo os jovens artistas acordem, e que seria interessante conhecê-los aqui.

Por outro lado, não acredito que seja necessário fazer predominar na França e de propagar no estrangeiro toda música francesa, qual que seja o seu valor.

Vejam, Senhores, que sobre vários pontos minha opinião é assaz diferente da vossa, para me permitir a honra de figurar entre vós.

Espero todavia continuar a "fazer ato de Francês" e "contar entre os que serão lembrados". 
Queiram acreditar, Senhores, a expressão de meus distintos sentimentos.

Maurice Ravel

(BNF. Mu. L.a. Ravel vol. 89, 184)

De volta ao fronte, Ravel adoece novamente, e em outubro desse mesmo ano é operado. De acordo com carta enviada à Sra. Casella em 8 de outubro de 1916, o compositor aproveita de seu tempo, escreve aos amigos sobre sua rotina de caserna, dedica-se à leitura, documentando-se sobre o século XVIII, pois nesse momento trabalhava, mesmo se precariamente devido às condições em que se encontrava, na composição do Tombeau de Couperin, que havia iniciado em Saint Jean de Luz durante a primavera de 1914:

Levo uma vida monótona e singular: convivo com "poilus" com os quais tenho uma relação de camaradagem. Verdadeiros "poilus". Revoltados, de um pessimismo cego, de um egoísmo baixo... e que se tornarão heróis em algumas semanas. No meio disso, leio obras sobre o século XVIII e um estudo sobre Mallarmé. Se encontrar minha mãe, o que a fará muito feliz, não diga a ela sobre minha operação, nem mesmo sobre o hospital pois ela não sabe de nada. (In: Marnat, 1986, p. 420)

Em novembro, após operação realizada no fronte, Ravel volta à Paris para sua convalescença. Esse período de repouso permitiria ao compositor estar ao lado da mãe, doente, e que viria a falecer em 5 de janeiro de 1917. Conforme testemunho do próprio compositor, este seria o golpe mais rude de toda sua existência ${ }^{24}$, e o silêncio epistolar desse período, exprimiria sua prostração. Seu retorno na zona do fronte é um fracasso, e em uma de suas últimas cartas como soldado de guerra escreve a Sra. Dreyfus sobre a sua dor:

\footnotetext{
${ }^{24}$ Trecho da carta escrita em 27 de dezembro de 1919 à Ida Godebska: Logo serão 3 anos que ela partiu, e meu desespero aumenta dia após dia. Eu penso, desde que voltei ao trabalho, que não tenho mais esta cara presença silenciosa me envolvendo em sua ternura infinita, o que era, e agora percebo mais do que nunca, minha única razão de viver. (Orenstein, 1989, p. 177)
} 
Moralmente é terrível... não faz muito tempo que escrevia para ela, que recebia suas pobres cartas, que me entristeciam...e portanto era para mim uma grande alegria. Estava ainda contente nesse momento, apesar desta angústia surda...Não imaginava que chegaria tão rápido. Nesse momento, sinto um terrível desespero, os mesmos pensamentos ternos...

Não é bom que eu fique longe de meu pobre Éduard.

Meu capitão me assegura que devo reagir. (...) Mais do que nunca, eu vos sou grato por não ter me deixado sozinho. Aqui, sinto-me mais isolado do que em qualquer outro lugar, no meio de camaradas amáveis, alegres, porém tão longe de mim... (Orenstein, 1989, p. 165)

Devido sua condição física e psicológica, Ravel é reformado em março de 1917, e em junho retoma a composição da suíte Le Tombeau de Couperin: “Enfim, eu trabalho. Isso me faz suportar tantas coisas". (In: Marnat, 1986, p. 423)

\section{Considerações finais}

É interessante esclarecer sobre a posição de Maurice Ravel em relação ao nacionalismo. Sua postura é radical enquanto adesão ao nacionalismo da defesa de seu país como nação, até a necessidade de participar ativamente como soldado, quando nada o obrigava, conforme ele mesmo afirmou em resposta à Liga Nacional: eu posso somente louvar vossa "idéia fixa do triunfo da Pátria", que persegue a mim mesmo desde o início das hostilidades. (...) Esta necessidade de ação me é tão intensa que me fez deixar a vida civil, quando nada me obrigava. Sua posição não é radical quando se trata de um nacionalismo artístico e cultural, Ravel não é obtuso e obcecado, conforme podemos constatar em sua resposta à Liga Nacional. As obras escritas durante os anos de Guerra, o Trio para piano, violino e violoncelo (1914), obra em que resgata elementos do folclore nacional; as Trois Chansons para coro misto sem acompanhamento, em que escreve a letra para as três canções (1914), a Suíte para piano solo Le Tombeau de Couperin (1914-1917), homenagem aos amigos mortos nos campos de batalha e 
à música francesa do séc. XVIII, seriam a prova de seu envolvimento estético com o movimento em questão.

Nesse sentido, Maurice Ravel irá operar um neoclassicismo pessoal e aderir ao nacionalismo de forma racional, exaltando o folclore nacional e restaurando a obra de um mestre francês do passado, François Couperin, esquecido durante o século que seria dominado por compositores do país inimigo, o Romantismo. Dessa forma Ravel lutou pela autenticidade da música francesa, buscando na cultura de seu país e no significativo passado francês do século XVIII fundamentos e pilares para a criação de uma nova música com uma identidade e características nacionais.

\section{Referências}

BENEDETTI, Danieli V. L. Le Tombeau de Couperin (1914-1917) de Maurice Ravel: obra de uma guerra. Tese de Doutorado. Universidade de São Paulo ECA/USP/FAPESP, 2008.

CHALUPT, René. Ravel au miroir de ses lettres. Paris: Laffont, 1956.

DIVERSOS AUTORES. La Musique Pendant la Guerre. Revue Musicale Mensuelle. Directeur: Charles Hayet. Paris: Comptoir Géneral de Musique, no 1 - 10/10/1915. LALOY, Louis. Le Tango. La Revue Musicale. Paris: 1/02/1914, pp. 47-49. MARNAT, Marcel. Maurice Ravel. Paris: Fayard, 1986.

ORENSTEIN, Arbie. Lettres et entretiens - Maurice Ravel. Paris: Flammarion, 1989. RAVEL, Maurice. Lettres à Roland Manuel et à sa famille. Paris: Calligrames, 1989. . Correspondência do compositor, 1900-1933, catalogadas por A. Bloch Michel. Paris: Bibliothèque Nationale de France, Mu. L.a. Ravel vol. 89 e 90.

ROUSSEAU-PLOTTO, Étienne. Ravel, portraits basques. Paris: Séguier, 2001. ROY, Jean. Lettres à Roland Manuel e à sa famille. Quimper: Caligrammes, 1986. 